\title{
On the E-learning Technology of Education in University
}

\author{
Fei Long \\ Foreign language Department, Harbin University of Commerce \\ Communication University of China \\ Harbin, Hei Longjiang Province, China \\ 13021920933@163.com
}

\begin{abstract}
The emergence of E-learning technology provides many approaches for the learners interacting with multi-media, which could be used in various teaching methodologies, however, it is not applied extensively in the educational field, since the lack of necessary digital literacy of teachers and learners. Based on the background and features of E-learning, the paper points out content design and evaluation elements of E-learning. In the network era, we should make full use of the convenience brought by computer, it is imperative to improve efficiency on teaching.
\end{abstract}

Keywords-E-learning; Design principles; Evaluation mechanism

\section{INTRODUCTION}

Recently, with the development of multi-media and network technique, E-learning has become the major way of studying for people, which breaks the limitations of time and space on traditional teaching, providing a relaxed, free and open environment for studying. The use of information and communication technologies in higher education has proved to be very effective in different educational environment [1].

E-learning is an open and creative for educational thought and mode, which improves the quality of education, also enhances the academic communication between universities. Based on the background and features of E-learning, this paper points out the content design and evaluation elements of Elearning, theses two strategies change the traditional role of teacher, which improve the efficiency on teaching.

\section{E-LEARNING EDUCATION}

The concept of E-learning was stated from educational technical white papers of United States Department of Education: E-learning refers to the education and relevant services based on the internet, which offers learners a new learning model, providing the possibility for lifelong learning, because its variability of time and space. E-learning changes the relations between teaching and learning, and the roles teachers played, then deepens the significance of education itself.

E-learning was applied extensively in educational field since 1990s. However, the definition has not been unified. Some researchers argue that E-learning can deliver teaching content through electronic media, which includes internet, satellite broadcast, video and audio, interactive TV or disk and so on [2]. Others argue that E-learning is a platform based on internet for learning, which deliver the value of teaching through network communication, cooperation, knowledge transmission to the learners and business organization [3]. Though most researchers hold that, E-learning could be applied to any other electronic media besides internet, the network technology makes the way of learning via E-learning accepted by more and more educational institutions and business organizations [4]. E-learning has become the important part of educational service market of increasingly fierce competition. In order to satisfy the various needs of customer education, education services institution provides on-line courses, test and educational counseling etc.

Most of learners attended the E-learning are active ones [5], which are opposite to the students who obtain information from teachers passively. The E-learning just conforms to the condition, active learning is the first requirement for the learners. E-learning creates a new way of learning, which based on internet media, student-centered learning method. Due to its advantages, the learners become more active than before during study [6].

With the popularization of internet, we change our mind on the acceptance of the way of teaching. The NMC Horizon Report: 2016 Higher Education Edition has proposed:

Significant challenges impeding technology adoption in Higher Education:

1) Solvable challenges: Those that we understand and know how to solve.

- Blending formal and informal learning

- Improving Digital literacy

2) Difficult challenges: Those that we understand but for which solutions are elusive

- Competing models of Education

- Personalizing learning

3) Wicked challenges: Those that are complex to even define, much less address

- Balancing our connected and unconnected lives 


\section{- Keeping education relevant}

The trends depend on the technology, the only way for challenges is change. We can observe from following comprehensive graph (Shown in Fig.1 [7]) that the technology will lead the trends, however, the challenges would not be solved with the changing technology directly even though it has become well-developed, the affective computing and robotics has been spread and applied, the difficult and wicked challenge still exist. Maybe this is the fantastic place, where combined education and technology. The former patterns and way of thinking can not cater the change of technology. Only the individual and its system do the self-innovation.

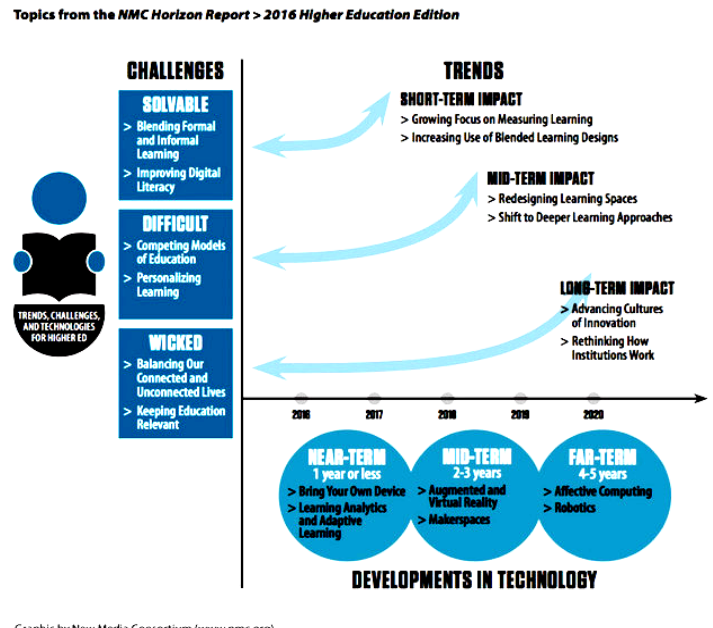

Fig. 1 Topics from the NMC Horizon Report

The challenges for the students lie in how to study further on their own, which can balance the online and off existence. While, for the teachers or subject of higher education system, the challenges tend to be the change of mode, from single model to open and multi-models.

The tradition education system has classified college, subject and course, which is good to the development of fine and specialization. However, nowadays, which just impede the adequacy of education, just contrasting with the freedom and variety of online learning space.

\section{FEATURES OF E-LEARNING}

Besides the advantage of high quality resource-sharing effectively, the features of E-learning in the big data era including:

\section{A. The Reform from Right to Education to Right to Learn}

What depends on learning objective and content? The emergence of E-learning indicates the dissolving of right of traditional education. The UNESCO has proposed the right of learning in 1986, which is part of human right. The two concepts are nearly the same in the traditional education system. However, the right to education should be part of the right to learn. In a learning society, the source of knowledge does not only come from university, besides which, we can obtain information from other approaches, thus, the way for education does not depend on receiving.

The right to learn is embodied in the learning autonomy, including the independent choice for learning content, learning patterns, learning time and space. For the traditional education system, the choice is presented by universities, subjects and teachers, which could not be guaranteed adequately. E-learning realized the learning choice, whose precondition is that it can suppose students' choice by its own technique, provision resources and learning model.

\section{B. The Intelligence Assistance of Computer}

E-learning system can record the learning trace of learners and its relevant learning material. The technique of learning analysis contributes to develop the value of data of learning process, which makes it as the foundation of decision and process optimization. In the era of big data, learning process for the learners has practical value. Individuation is the important feature for E-learning, but for the limitation of technical condition, the level of individuation needs to be improved. With the assistance of big data analysis, the individuation push of learning resource and the analysis of learning quality will be solved soon.

\section{Ubiquitous Learning on Multi-terminal}

The mode of ubiquitous learning is an important trend after the emergence of mobile terminal for E-learning. It realizes the communication without considering time and place for learn, we can obtain the information only if we want. The situation cognition technique helps the learners to obtain context.

\section{Generative Resources}

With the change of main educational object, the suppliers of learning resources have changed as well. MOOCs based on the curriculum of module that embodied the important trend of E-learning, the generative features of resources, which reflected the diversified characteristics of learning. The designers and developers of resources turns to multi-main providers from authority. The traditional education resource can't meet the needs of quick change learning in social learning network.

\section{THE SIGNIFICANCE OF E-LEARNING APPLICATION}

Recently, micro-courses online video spring up, however, the correlation is not too tight with professional courses. Most of students would not watch the videos actively, if we can design these videos related to professional courses, making use of existing network resources as their relevant knowledge after class, which could be more significant than before. Some teachers worry about the quality of the learning effect of students, in fact, it is not the point, the right design principles and evaluation systems should be accepted in a proper way.

Digital strategies are not so much technologies as they are ways of using devices and software to enrich teaching and learning, whether inside or outside of the classroom. Effective digital strategies can be used in both formal and informal 
learning; what makes them interesting is that they transcend conventional ideas to create some new concept.

\section{A. Content-Design of E-learning}

A good design tries to help students to practice system properly and easily, but not put trouble to them [8]. The design principles should follow its functionality, guidance, restrictions and feedback, meanwhile, the design of unit-knowledge should be combined with the course features. However, what kind of design can promote active study behavior of E-learning? On one hand, we must get rid off the traditional typical knowledge presentation as linearity. The knowledge presentation structure of branches, network and modularity should be adopted so as to it accords with the original cognitive structure of store knowledge of human brain. On the other hand, from the respect of knowledge property, trying to break out the representation of traditional and factual knowledge, increasing solution to knowledge of different reappearing of situation design.

The detailed design of E-learning course is also important, otherwise, the learners would be confused. Robin Williams has put forward the relative property, repeatability, linearity, similarity for the importance of visual effect and space distribution of design, which could be use in the course design to improve learning efficiency [9]. The vision comparison can bring clear and transparent to understand the vital point. For instance, magnify the title and shrink the subtitle gradually, which is beneficial learners to search significant information quickly. Repeatability does not mean we do not have innovativeness, the learners are familiar with distribution of modules in the middle and later periods, and then the purpose and process of learning is clear gradually. The principal of linearity is to prompt designers to keep the linearity of content, presenting the relationship between contents by some methods, in order to master the hierarchical relation of items for the learners. The similarity emphasizes the correlation between contents, briefly, the designers try to put the relative items together, which is convenient for the students to understand. The reasonable design for E-learning saves time for learners, avoiding the troubles for not finding the homework.

\section{B. Evaluation elements of E-learning}

Bernard Bull argues that the design of online courses just like the mode of buffet, firstly, each student should set a concrete target and try to know how to gain points. Given the freedom of selection space, their motivation for learning has been inspired, their improvement for learning ability has been increased, and thereby the research results could be presented by various ways.

Theoretically, three elements could evaluate the effect of Elearning: regulation of learning environment; interaction with learning content; interaction with virtual learning service and students.

\section{1) Regulation of learning environment}

Regulation of learning environment refers to the ability of self-motivation, which means that the learners should make clear whether the information communicated is what they need to learn. Facing the vast training material, the learners must make sure the problems of their ability, reflecting their personal situation faithfully. With the assistance of objective evaluation, they could ensure their basic training needs.

Basically, E-learning requires the participants to regulate time and learning resource effectively. The traditional lecture makes the learners as passive state. They just listen and absorb the information that maybe useful in future. However, Elearning requires grasping their learning experiences, including setting up a learning target and drawing up a plan.

\section{2) The ability of metacognition or self-awareness}

Metacognition or self-awareness ability refers to the high degree of analytical behavior of learning behavior to control the learning process of learning. Although the designer of Elearning will design the learning experiences, the learners of Elearning should know their own learning style and preference, then organize their learning experiences according to learning strategies.

The metacognitive ability also indicates the learning process of self-evaluation and self-regulation, some learners are not sure of their learning experience, because of the lack of outside feedback, which makes them begin to doubt the target of themselves. It is use to supervise the process of implementation plan, focusing on whether the learners are studying but not for passing the exam.

\section{3) Interaction with virtual learning service and students}

Interaction with virtual learning service and students, also means the cooperative ability. The learners spread their idea via virtual class is totally different from in the realistic one.

For the traditional class, the teacher is not necessary to offer formal feedback, however, though without speaking, they can act with behaviors inevitably. As to the virtual courses, if the learners want to these feedbacks, they must understand the proper time for asking for them. Meanwhile, some on-line activities do not need teachers' regulation process, therefore, the feedbacks from partners are necessary. In order to achieve the particular goal, the learners of E-learning must understand the type of feedback they need and the way to obtain it. The successful learners seek and offer the feedbacks and combine them with learning target and expectation of training.

If all the learners can study actively, the teachers who help them to set up self-direction, meta-cognition and cooperative ability would save more time and energy to assist other more students.

\section{CONCLUSION}

Due to the form of elective course, the number of students is too much, caused the limited chance for students to express opinions. The network techniques offer platforms for learners to speak and express opinions freely, meanwhile, their critical thinking ability is cultivated. With the aid of the internet, many organizations and universities have adopted the idea of applying the e-learning system, which is considered as one of the most important services provided by the internet [10].

The role teachers played is to monitor and guide, they solve problems proposed by students in real time, therefore, building up a bridge between classes no matter in or outside. In the network era, we should make full use of the convenience 
brought by computer, it is imperative to improve efficiency on teaching.

\section{REFERENCES}

[1] E-learning and face to face mixed methodology: Evaluating effectiveness of e-learning and perceived satisfaction for a microeconomic course using the Moodle platform [J]. Isabel Novo-Corti, Laura Varela-Candamio, Maria Ramil-Diza. Computers in Human Behavior. 2013(2).

[2] Engelbrecht E. A Look at E-learning Models: Investigating Their Value for Developing an E-learning Stratetigy [J]. Unisa Press, 2003, 25(2) pp:38-47

[3] Kelly T M, Bauer D K. Handbook on Knowledge Management [M] Springer Berlin Heidelberg, 2003, pp: 511 - 532.

[4] Alavi M, Leidner D. Research Commentary: Technology Mediated Learning - A Call for Greater Depth and Breadth of Research [J]. Information Systems Research, 2001, 12(1), pp: 1-10.
[5] Bonwell C C, Eison J A. Active Learning: Creating Excitement in the Classroom. [D]. Washington, DC: George Washington University, 1991.

[6] Huffaker D A, Calvert S L. The New Science of Learning: Active Learning, Metacognition, and Transfer of Knowledge in E - learning Applications [J]. Journal of Educational Computing Research, 2003, 29 (3) pp: 325 - 334

[7] Topics from the NMC Horizon Report [J]. 2016 Higher Education Edition

[8] Don Norman, Things: Revised and Expanded Edition, MIT Press [D]. Novermber5, 2013, pp: 23.

[9] Robin Williams, The Non-Designers Design Book, Peachpit Press [D]. 2003(8), pp: 123.

[10] Learning style as a factor which affects the quality of e-learning [J] Suzana Markovi, Nenad Jovanovi, Artificial Intelligence Review. 2012(4). 